\title{
EDITORIAL
}

\section{FORMACIÓN EN HERIDAS EN EL GRADO DE ENFERMERÍA}

\author{
J. Javier Soldevilla Agreda \\ Director Gerokomos
}

Douglas Queen (2010) realizó una estimación de la situación mundial de pacientes con heridas mediante la combinación de muchos estudios individuales-regionales-nacionales, determinando que un mínimo de 300 millones de personas en el mundo presentarían heridas agudas, al menos 100 millones heridas traumáticas y un mínimo de 20 millones heridas crónicas. En general, un total mínimo de 400 millones de personas en el mundo se enfrenta a una herida.

Sasanka Chatterjee (2012) afirmó que, en el curso de la vida, casi el $10 \%$ de la población desarrollará una herida de evolución crónica.

Nadie creo ponga en duda la abultada presencia de estas lesiones en la población, sin detallar ahora las graves repercusiones que las acompañan en términos de calidad de vida, morbimortalidad e implicaciones económicas, éticas y legales.

Las heridas se generan y son atendidas en todos los contextos asistenciales y sin exclusividad, pero mayoritariamente, por enfermeras en primera instancia y habitualmente de forma continuada mientras no se resuelve esta falla de salud.

En el último cuarto de siglo se ha avanzado enormemente en el conocimiento de las heridas crónicas complejas, todavía más huérfanas en credo que el resto, han proliferado investigaciones científicas de calidad consolidando la evidencia que envuelve su atención y muchas lideradas por enfermeras, se ha producido un sereno reconocimiento de profesionales expertos y acreditados en su atención, desarrollado figuras de profesionales de práctica avanzada y especializadas unidades-clínicas de heridas. En paralelo, en los últimos años ha nacido una elevada oferta de cursos de experto y másteres universitarios centrados en esta materia y, por ende, centenares de egresados capacitados y con un alto nivel de competencia en la atención de personas con heridas o en riesgo de padecerlas están presentes en nuestro medio, pero, en este mismo tiempo de historia de crecimiento que relatamos, seguimos contemplando en nuestro país y otros de su entorno cultural, especialmente, cómo las enfermeras (no quiero referirme a otras disciplinas todavía más afectadas), en su formación de grado, apenas acarician, mayoritariamente de forma dispersa, desintegrada y superficial, conocimientos sobre heridas, su etiología y diagnóstico, su diversidad, su abordaje preventivo o terapéutico, pero además, por lo recalado, lo recibido, envuelto en una inexplicable falta de actualización en los conocimientos acercados en el aula y una desigual y a menudo confusa enseńanza clínica, aliada con el interés, el deseo, la formación de aquellos que tienen ese encargo. Muchos, demasiados maestrillos y demasiados librillos, que generan un desconcierto en los futuros profesionales, embriagados todavía en demasiadas circunstancias con directrices erróneas y me atrevería a decir, inseguras, peligrosas, que creen son dictados de la Ciencia. Al día siguiente de su graduación, esas enfermeras tendrán la responsabilidad directa sobre pacientes con heridas allí donde se encuentren.

Permítanme con estas líneas luctuosas, por su trascendencia, proponer un giro en la academia, en este nivel que como en la formación posgraduada se está consolidando, facilite ganar la batalla a estas lesiones, ya de por sí envueltas en complejidad, tardanza y sufrimiento.

Esa transversalidad que las heridas soportan, en cuanto a grupos etarios, vinculaciones etiológicas, niveles asistenciales donde se presentan y se siguen, desigualdad en interés de las partes, en esa patente de corso que otorga capacidad de obrar a todo profesional, sin necesidad de demostrar su capacitación en esta área, se ejemplariza también en los programas formativos de nuestras escuelas y facultades, que tratan a veces de soslayo el tema en asignaturas diferentes y sin integración alguna, apenas simbólicos los centros que han dado un paso más allá, promoviendo materias optativas y creo ninguna obligatoria, afianzando esa heterogeneidad cómplice y rúbrica de la formación clínica recibida en paralelo.

En los últimos años, sociedades científicas relacionadas con la atención en heridas en Europa han trabajado propuestas formativas sobre heridas para enfermería en diferentes niveles del Marco Europeo de Cualificaciones con objetivos de aprendizaje necesariamente relacionados y que pueden integrarse en los planes de estudio de esa formación de pregrado para adaptarse a las competencias que se esperan de ellos.

En el año 2016, desde el seno del GNEAUPP y SILAUHE quisimos sumarnos a este debate y acciones (ya iniciado en 2005 con la propuesta de seminarios de actualización para docentes de enfermería, con moderada acogida) convocando el $1^{\text {er }}$ Encuentro Iberolatinoamericano de Facultades y Escuelas con Programas Formativos en Heridas y su segunda edición en el cercano mes de noviembre en Toledo, perseguimos continuar con el análisis entre facultades y escuelas universitarias responsables de formación en heridas en sus distintos niveles y trasladar a la comunidad académica propuestas concretas sobre lo que se entiende sería necesario y preceptivo implementar en los currículos en esta materia, especialmente y declaradamente en nuestro grado de Enfermería.

Ojalá podamos cubrir al menos con el fin de establecer un documento base de recomendaciones sobre objetivos de aprendizaje, contenidos mínimos, herramientas pedagógicas sobre heridas crónicas en el grado de enfermería, que difundiremos a todos y que los responsables se hagan eco.

Entiendo que es necesario acometer sin demora esta reforma específica en la formación básica de las enfermeras que se traducirá de manera temprana en una práctica más segura y eficiente de tantos y tantos heridos 